\title{
Fast-food and commercial baked goods consumption and the risk of depression
}

\author{
Almudena Sánchez-Villegas ${ }^{1,2, *}$, Estefania Toledo², Jokin de Irala², \\ Miguel Ruiz-Canela ${ }^{2}$, Jorge Pla-Vidal ${ }^{3}$ and Miguel A Martínez-González ${ }^{2}$ \\ ${ }^{1}$ Centre for Health Sciences, Department of Clinical Sciences, University of Las Palmas de Gran Canaria, \\ PO Box 550, CP 35080, Las Palmas de Gran Canaria, Spain: ${ }^{2}$ Department of Preventive Medicine and Public \\ Health, University of Navarra, Pamplona, Spain: ${ }^{3}$ Department of Psychiatry and Medical Psychology, Clinic of \\ the University of Navarra, Pamplona, Spain
}

Submitted 31 January 2011: Accepted 16 June 2011: First published online 11 August 2011

\begin{abstract}
Objective: Whereas the relationship between some components of diet, such as $n-3$ fatty acids and B-vitamins, and depression risk has been extensively studied, the role of fast-food or processed pastries consumption has received little attention. Design: Consumption of fast food (hamburgers, sausages, pizza) and processed pastries (muffins, doughnuts, croissants) was assessed at baseline through a validated semi-quantitative FFQ. Participants were classified as incident cases of depression if they reported a physician diagnosis of depression or the use of antidepressant medication in at least one of the follow-up questionnaires. Cox regression models were fit to assess the relationship between consumption of fast food and commercial baked goods and the incidence of depression.

Setting: The SUN (Seguimiento Universidad de Navarra - University of Navarra Follow-up) Project, Spain.

Subjects: Participants ( $n$ 8964) from a Spanish cohort.

Results: After a median follow-up of $6 \cdot 2$ years, 493 cases of depression were reported. A higher risk of depression was associated with consumption of fast food (fifth (Q5) $v$. first quintile (Q1): hazard ratio $(\mathrm{HR})=1 \cdot 36$; $95 \%$ CI 1.02, 1.81; $P$ trend $=0 \cdot 003)$. The results did not change after adjustment for the consumption of other food items. No linear relationship was found between the consumption of commercial baked goods and depression. Participants belonging to consumption quintiles Q2-Q5 showed an increased risk of depression compared with those belonging to the lowest level of consumption (Q1; HR $=1 \cdot 38$; 95\% CI 1·06, 1·80). Conclusions: Fast-food and commercial baked goods consumption may have a detrimental effect on depression risk.
\end{abstract}

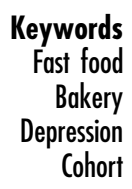

Depression affects about 121 million people worldwide; it is one of the leading global causes of disability-adjusted life years and the main cause in middle- and high-income countries $^{(1,2)}$. However, little is known about the role of diet in the development of depressive disorders. Evidence suggests a preventive role for certain nutrients such as B-vitamins or $n-3$ fatty acids ${ }^{(3-6)}$ and recently for olive $\mathrm{oil}^{(7,8)}$. Also, a 'healthy' dietary pattern, such as the Mediterranean diet, has been related to a lower risk of depression ${ }^{(9)}$. In spite of this, the effects on depression of other detrimental diet components are not yet disentangled. Several cross-sectional studies have analysed the association between the consumption of these products and depressive symptoms or perceived stress. For example, Liu et al. found a significantly lower prevalence of depression symptoms for persons with a low consumption of 'ready-to-eat' foods and for low-frequency fast-food eaters ${ }^{(10)}$. Similarly, depressive symptoms were associated positively with consumption of high-energy sweets in the study by Jeffery et al. ${ }^{(11)}$. Mikolajczyk et al. found a positive association between fast-food, snacks and sweets consumption and depressive symptoms and perceived stress among female students ${ }^{(12)}$. Moreover, a recent analysis has found that a pattern rich in processed or fried foods, refined grains, sugary products and beer was significantly related to higher scores in the General Health Questionnaire GHQ-12 (a test designed to measure psychological symptoms). Also, a direct (although not significant) association between the mentioned pattern and a clinical depression diagnosis was described ${ }^{(13)}$. However, the cross-sectional design of the mentioned studies advises caution in the interpretation of their results. 
Cross-sectional studies are weak to infer cause-and-effect relationships. In these studies exposure was ascertained simultaneously with disease and, therefore, their findings could also be interpreted as the result of reverse causation bias, i.e. depression may lead to poorer dietary habits with higher consumption of these types of products ${ }^{(14)}$. In fact, some studies have also observed higher energy and fat intakes under stressful situations ${ }^{(15)}$.

To our knowledge, only one prospective study has analysed the effects of processed food items but focusing on depressive symptoms and not on a medical diagnosis of depression. The results obtained in 2009 in the Whitehall II prospective cohort showed that a food pattern characterized by a high consumption of sweetened desserts, fried food, processed meat, refined grains and high-fat dairy products was associated with higher scores on the Center for Epidemiologic Studies-Depression (CES-D) scale ${ }^{(16)}$.

The aim of the present study was to analyse the potential detrimental role of fast-food and commercial baked goods consumption on the occurrence of clinical depression in a prospective cohort study of university graduates in Spain.

\section{Materials and method}

\section{Study population}

The 'Seguimiento Universidad de Navarra' (SUN) Project is a multipurpose Spanish cohort composed of former students of the University of Navarra, registered professionals from some Spanish provinces and other university graduates. Information with regard to exposures and outcomes is gathered by biennial mailed questionnaires. The recruitment of participants started on 21 December 1999 and is permanently ongoing because it is a dynamic cohort with recruitment continuously open. The overall follow-up rate approaches $90 \%$. Further details about the methodology and characteristics of participants can be found in a previously published report ${ }^{(17)}$.

Up to January 2007, 16358 participants had completed the baseline questionnaire of the SUN Project. Participants were excluded from the present analyses if they were lost to follow-up, had extreme values for energy intake (less than $3347 \mathrm{~kJ} / \mathrm{d}(800 \mathrm{kcal} / \mathrm{d})$ or more than $16736 \mathrm{~kJ} / \mathrm{d}$ $(4000 \mathrm{kcal} / \mathrm{d})$ in men and less than $2092 \mathrm{~kJ} / \mathrm{d}(500 \mathrm{kcal} / \mathrm{d})$ or more than $16644 \mathrm{~kJ} / \mathrm{d}(3500 \mathrm{kcal} / \mathrm{d})$ in women), had a history of CVD, diabetes, hypertension or dyslipidaemia at baseline, or were users of antidepressant medication or had reported a previous clinical diagnosis of depression at baseline. Additionally, participants with missing values for BMI were also excluded from the analyses. Finally 8964 participants who had completed at least one follow-up questionnaire were included in the present study (Fig. 1).

The study was approved by the Institutional Review Board of the University of Navarra. Voluntary completion of the first questionnaire was considered to imply informed consent.

\section{Exposure assessment}

Dietary intake was assessed at baseline with a validated semi-quantitative $\mathrm{FFQ}^{(18)}$. Nutrient intakes of 136 food items were calculated as frequency multiplied by the nutrient composition of a specified portion size for each food item, using an ad hoc computer program specifically developed for this aim. A trained dietitian updated the nutrient database using the latest available information included in food composition tables for Spain.

The consumption of hamburgers, sausages and pizza was summed up to calculate total fast-food consumption. Muffins, doughnuts, croissants and other commercial baked goods integrated the group of commercial baked goods. The consumption of fast food and commercial baked goods was adjusted for total energy intake using the residual method and quintiles were built.

\section{Outcome assessment}

Participants were classified as having incident depression when they were free of depression and antidepressant treatment at baseline and responded positively to the question 'Have you ever been diagnosed as having depression by a medical doctor?' or reported the habitual use of antidepressant drugs in any of the follow-up questionnaires. Antidepressant use was ascertained through an open question in which the participants reported their medications.

A self-reported physician-made diagnosis of depression demonstrated acceptable validity in a specific validation study conducted in a sub-sample of our cohort by means of the Structured Clinical Interview for DSM-IV (SCID-I) as the criterion standard, applied by experienced psychiatrists masked to the answers to the questionnaires. SCID-I main body consists of nine diagnostic modules, including mood episodes and mood disorders differentially. The percentage of confirmed cases of depression was $74.2 \%$ (95\% CI $63 \cdot 3,85 \cdot 1)$. Moreover, $81 \cdot 1 \%(95 \%$ CI $69 \cdot 1,92 \cdot 9)$ of the sub-sample classified as not depressed by the question were free of depression. The estimated sensitivity and specificity values for our population were 0.37 and 0.96 , respectively ${ }^{(19)}$.

\section{Assessment of other covariates}

The baseline questionnaire also included different items related to lifestyle, anthropometric and sociodemographic variables, with forty-six items for men and fifty-four items for women. Information on sex, age, marital status, employment status, weight, height, smoking status, physical activity and medical history (e.g. prevalence of chronic diseases) was collected. BMI was calculated as weight (in kilograms) divided by the square of height (in metres).

Physical activity was assessed through a validated physical activity questionnaire with data about seventeen activities $^{(20)}$. Leisure-time activities were computed by assigning an activity metabolic equivalent (MET) score to 


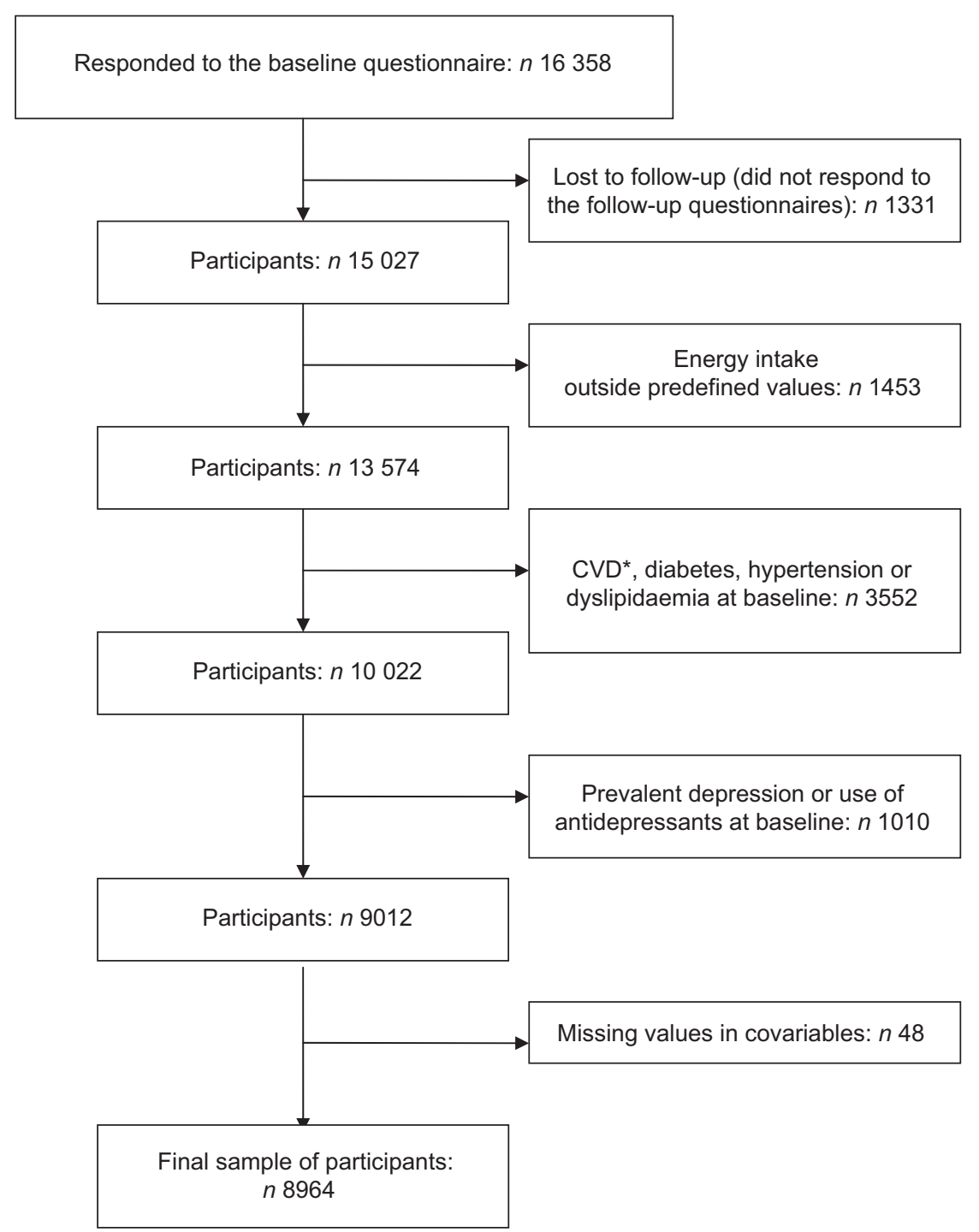

Fig. 1 Flowchart of participants in the present analysis; SUN Project (Seguimiento Universidad de Navarra - University of Navarra Follow-up), Spain ( ${ }^{\circ} \mathrm{CVD}=$ myocardial infarction, stroke, atrial fibrillation, paroxysmal tachycardia, coronary artery bypass grafting or other revascularization procedures, heart failure, aortic aneurism, pulmonary embolism or peripheral venous thrombosis)

each activity, multiplied by the time spent in each activity and summing up all activities.

\section{Statistical analysis}

Cox (proportional hazards) regression models were fit to assess the relationship between consumption of the combination of fast food and commercial baked goods (quintiles) and the incidence of depression. Moreover, the contribution of fast food and commercial baked goods to the risk of depression was ascertained separately. Hazard ratios (HR) and their 95\% confidence intervals were calculated with the lowest category of consumption as the reference category. Tests of linear trend across increasing quintiles were conducted by assigning the medians to each category; this variable was treated as continuous.

Participants contributed to the follow-up period up to the date of return of their last questionnaire, death or diagnosis of depression, whichever came first. The Cox model used age as the underlying time variable. We stratified by age (in 5-year intervals) to control for calendar-period and birth cohort effects ${ }^{(21)}$.

Other potential confounders included as covariates in the multiple Cox models were sex, baseline BMI $\left(\mathrm{kg} / \mathrm{m}^{2}\right.$, continuous), total energy intake $(\mathrm{kJ} / \mathrm{d}$, continuous), physical activity during leisure time (MET $\times \mathrm{h} /$ week, continuous) and smoking (never, past and current smokers).

We conducted sensitivity analyses, and repeated all of the analyses: (i) after adjusting for the consumption of healthy food items (fruits and nuts, vegetables, legumes, fish and olive oil); (ii) after additional adjustment for some correlates of health consciousness or proxies of an overall healthier lifestyle, such as marital status (married, other), number of children (continuous), employment status (employed, unemployed), number of work hours 
per week (none, $<35,35-45,>45$ ), days per week of consumption of alcoholic beverages (never, 1-2, 3-5, $>5$ ), driving after alcohol intake (no, yes), use of seat belt (no, yes), periodic dental check-ups (no, yes) and periodic medical check-ups (no, yes); among women, the analyses were also adjusted for menopausal status, previous mammography screening and use of the Papanicolaou test; and (iii) after excluding early cases (to avoid a possible reverse causation bias).

The statistical software packages SPSS for Windows version $14 \cdot 0$ (SPSS Inc., Chicago, IL, USA) and STATA Intercooled version $9 \cdot 0$ (StatCorp., College Station, TX, USA) were used for statistical analyses. All $P$ values are twotailed and statistical significance was set a priori at $P<0 \cdot 05$.

\section{Results}

The main baseline characteristics of the participants according to extreme quintiles of consumption of fast food and commercial baked goods are presented in Table 1. Participants with higher consumption of fast food and commercial baked goods (fifth quintile, Q5) were more likely to be single, younger, less active, and showed a worse dietary profile with less consumption of healthy food items such as fruits and nuts, fish, vegetables or olive oil. Some lifestyle characteristics, such as smoking and working time greater than $45 \mathrm{~h} /$ week, were also more prevalent in this group.
After a median follow-up of $6 \cdot 2$ years, 493 cases of depression were observed.

The association between successive quintiles of fastfood consumption and depression risk is shown in Table 2. A higher risk was found for the highest consumption of fast food in the four models. In model 2 (adjusted for the main potential confounders), consumption of fast food in the highest category (Q5) was associated with a $40 \%$ higher risk of depression (multiple-adjusted $\mathrm{HR}=1 \cdot 40$; $95 \%$ CI 1·05, 1·86). Moreover, a significant dose-response relationship was found ( $P$ for trend $=0 \cdot 001$ ).

A direct association was also found between commercial baked goods consumption and depression although no linear relationship was found in any of the four models (Table 3). The HR (95\% CI) for successive quintiles of consumption were $1 \cdot 00$ (reference), $1 \cdot 44$ (1.06, $1 \cdot 95), 1 \cdot 40(1 \cdot 01,1 \cdot 94), 1 \cdot 15(0 \cdot 82,1 \cdot 61)$ and $1 \cdot 43(1 \cdot 06$, $1 \cdot 93)$. When the analyses were repeated after merging participants belonging to the four upper quintiles (Q2-Q5) of consumption and comparing them with those participants with the lowest consumption, the results did not change. The HR for the Q2-Q5 $v$. Q1 in model 2 adjusted for the main potential confounders was 1.38 (95\% CI $1 \cdot 06,1 \cdot 80$ ).

We summed the quintile value for both items (fast food and commercial baked goods) to collapse the two constructs into one unhealthy diet variable (range: 2 to $10)$. We built three categories with this new variable $(<4$, $4-8,>8)$ and the multivariable-adjusted HR $(95 \% \mathrm{CI})$ of

Table 1 Baseline characteristics of the participants according to extreme quintiles of fast-food and commercial baked goods consumption*; SUN Project (Seguimiento Universidad de Navarra - University of Navarra Follow-up), Spain

\begin{tabular}{|c|c|c|c|c|}
\hline & \multicolumn{2}{|c|}{ Quintile of consumption of fast food } & \multicolumn{2}{|c|}{ Quintile of consumption of commercial baked goods } \\
\hline & Q1 ( $n$ 1793) & Q5 (n 1792) & Q1 ( $n$ 1793) & Q5 (n 1792) \\
\hline & $\%$ & $\%$ & $\%$ & $\%$ \\
\hline \multicolumn{5}{|l|}{ Sex } \\
\hline Men & $36 \cdot 8$ & $45 \cdot 8$ & $38 \cdot 8$ & $45 \cdot 0$ \\
\hline \multicolumn{5}{|l|}{ Smoking status } \\
\hline Ex-smoker & $31 \cdot 1$ & $21 \cdot 4$ & $29 \cdot 2$ & $21 \cdot 0$ \\
\hline Current smoker & $21 \cdot 8$ & $27 \cdot 5$ & $22 \cdot 6$ & $24 \cdot 8$ \\
\hline \multicolumn{5}{|l|}{ Marital status } \\
\hline Married & $54 \cdot 0$ & $39 \cdot 7$ & $51 \cdot 5$ & $44 \cdot 6$ \\
\hline Unemployed & $4 \cdot 6$ & $5 \cdot 1$ & $4 \cdot 4$ & $5 \cdot 4$ \\
\hline Driving after alcohol intaket & $48 \cdot 9$ & $53 \cdot 8$ & $50 \cdot 5$ & $52 \cdot 5$ \\
\hline Use of seat beltst & $88 \cdot 3$ & $86 \cdot 2$ & $90 \cdot 6$ & $83 \cdot 7$ \\
\hline \multicolumn{5}{|l|}{ Use of screening tests } \\
\hline Medical check-up & $63 \cdot 5$ & $69 \cdot 8$ & $65 \cdot 2$ & $70 \cdot 9$ \\
\hline Dental check-up & $90 \cdot 1$ & $90 \cdot 2$ & $91 \cdot 5$ & $90 \cdot 6$ \\
\hline Mammography & $40 \cdot 8$ & $21 \cdot 0$ & $36 \cdot 0$ & $26 \cdot 5$ \\
\hline Papanicolaou testł & $71 \cdot 2$ & $60 \cdot 0$ & $71 \cdot 1$ & $63 \cdot 4$ \\
\hline \multicolumn{5}{|l|}{ Menopausal status $\ddagger$} \\
\hline Postmenopausal & $32 \cdot 2$ & $20 \cdot 0$ & $26 \cdot 4$ & $22 \cdot 1$ \\
\hline \multicolumn{5}{|l|}{ Hours worked per week } \\
\hline None & $9 \cdot 6$ & $12 \cdot 9$ & $9 \cdot 6$ & $10 \cdot 2$ \\
\hline$<35$ & $18 \cdot 7$ & $15 \cdot 5$ & $18 \cdot 0$ & $14 \cdot 2$ \\
\hline $35-45$ & $43 \cdot 1$ & $37 \cdot 3$ & $43 \cdot 6$ & $40 \cdot 3$ \\
\hline$>45$ & $28 \cdot 6$ & $34 \cdot 3$ & $28 \cdot 8$ & $35 \cdot 3$ \\
\hline
\end{tabular}

${ }^{*}$ Adjusted for energy intake.

tIncludes only participants who drive.

flncludes only women. 
Table 2 Association between consumption of fast food (hamburgers, sausages, pizza) and depression*; SUN Project (Seguimiento Universidad de Navarra - University of Navarra Follow-up), Spain

\begin{tabular}{|c|c|c|c|c|c|c|c|c|c|c|c|}
\hline & \multicolumn{2}{|c|}{ Q1 } & \multicolumn{2}{|c|}{ Q2 } & \multicolumn{2}{|c|}{ Q3 } & \multicolumn{2}{|c|}{ Q4 } & \multicolumn{2}{|c|}{ Q5 } & \multirow[b]{2}{*}{$P$ for trend } \\
\hline & $\mathrm{HR}$ & $95 \% \mathrm{Cl}$ & $\mathrm{HR}$ & $95 \% \mathrm{Cl}$ & $\mathrm{HR}$ & $95 \% \mathrm{Cl}$ & $\mathrm{HR}$ & $95 \% \mathrm{Cl}$ & $\mathrm{HR}$ & $95 \% \mathrm{Cl}$ & \\
\hline $\begin{array}{l}\text { Energy-adjusted fast-food } \\
\text { consumption, median }(\mathrm{g} / \mathrm{d})\end{array}$ & \multicolumn{2}{|c|}{$1 \cdot 9$} & \multicolumn{2}{|c|}{$11 \cdot 5$} & \multicolumn{2}{|c|}{$19 \cdot 4$} & \multicolumn{2}{|c|}{$27 \cdot 6$} & \multicolumn{2}{|c|}{$41 \cdot 9$} & \\
\hline Cases/person-years & \multirow{2}{*}{\multicolumn{2}{|c|}{$\begin{array}{c}97 / 10378 \\
9 \cdot 3\end{array}$}} & \multicolumn{2}{|c|}{$\begin{array}{c}94 / 10301 \\
9 \cdot 1\end{array}$} & \multicolumn{2}{|c|}{$90 / 10391$} & \multicolumn{2}{|c|}{$94 / 10454$} & \multicolumn{2}{|c|}{$118 / 10374$} & \\
\hline Crude rates $/ 10^{3}$ & & & & $\cdot 1$ & & $\cdot 7$ & & 0 & & 4 & \\
\hline Model 1 & $1 \cdot 00$ & Ref. & $1 \cdot 00$ & $0 \cdot 75,1 \cdot 32$ & 0.98 & $0 \cdot 73,1 \cdot 32$ & $1 \cdot 04$ & $0 \cdot 78,1 \cdot 39$ & $1 \cdot 45$ & $1 \cdot 09,1 \cdot 92$ & 0.01 \\
\hline Model 2 & $1 \cdot 00$ & Ref. & 0.99 & $0 \cdot 74,1 \cdot 32$ & 0.97 & $0.72,1 \cdot 30$ & $1 \cdot 02$ & $0 \cdot 76,1 \cdot 38$ & 1.40 & $1 \cdot 05,1 \cdot 86$ & 0.01 \\
\hline Model 3 & $1 \cdot 00$ & Ref. & 0.99 & $0 \cdot 74,1 \cdot 32$ & 0.95 & $0 \cdot 70,1 \cdot 27$ & 1.00 & $0 \cdot 75,1 \cdot 35$ & $1 \cdot 36$ & $1 \cdot 02,1 \cdot 81$ & 0.03 \\
\hline Model 4 & $1 \cdot 00$ & Ref. & 0.99 & $0 \cdot 74,1 \cdot 32$ & 0.98 & $0.73,1 \cdot 32$ & 1.03 & $0.76,1.39$ & $1 \cdot 37$ & $1 \cdot 02,1 \cdot 83$ & 0.02 \\
\hline
\end{tabular}

Q1-Q5, quintiles of consumption; HR, hazard ratio; Ref., reference category.

Model 1: adjusted for sex and stratified for age.

Model 2: additionally adjusted for smoking (no response, non-smoker, former smoker and current smoker), leisure-time physical activity (metabolic equivalent score), total energy intake ( $\mathrm{kJ} / \mathrm{d})$ and $\mathrm{BMI}\left(\mathrm{kg} / \mathrm{m}^{2}\right.$ ).

Model 3: As model 2 additionally adjusted for commercial baked goods consumption.

Model 4: As model 2 additionally adjusted for healthy food items consumption.

${ }^{*} \mathrm{HR}$ estimated with Cox regression and $95 \% \mathrm{Cl}$. If the $95 \% \mathrm{Cl}$ interval does not include $1 \cdot 00$, the results are statistically significant (two-tailed $P<0 \cdot 05$ ).

Table 3 Association between consumption of commercial baked goods (muffins, doughnuts, croissants and other similar) and depression*; SUN Project (Seguimiento Universidad de Navarra - University of Navarra Follow-up), Spain

\begin{tabular}{|c|c|c|c|c|c|c|c|c|c|c|c|}
\hline & \multicolumn{2}{|c|}{ Q1 } & \multicolumn{2}{|c|}{ Q2 } & \multicolumn{2}{|c|}{ Q3 } & \multicolumn{2}{|c|}{ Q4 } & \multicolumn{2}{|c|}{ Q5 } & \multirow[b]{2}{*}{$P$ for trend } \\
\hline & $\mathrm{HR}$ & $95 \% \mathrm{Cl}$ & $\mathrm{HR}$ & $95 \% \mathrm{Cl}$ & $\mathrm{HR}$ & $95 \% \mathrm{Cl}$ & $\mathrm{HR}$ & $95 \% \mathrm{Cl}$ & $\mathrm{HR}$ & $95 \% \mathrm{Cl}$ & \\
\hline $\begin{array}{l}\text { Energy-adjusted commercial baked goods } \\
\text { consumption, median }(\mathrm{g} / \mathrm{d})\end{array}$ & \multicolumn{2}{|c|}{0} & \multicolumn{2}{|c|}{3.9} & \multicolumn{2}{|c|}{$7 \cdot 7$} & \multicolumn{2}{|c|}{$13 \cdot 0$} & \multicolumn{2}{|c|}{$36 \cdot 2$} & \\
\hline $\begin{array}{l}\text { Cases/person-years } \\
\text { Crude rates } / 10^{3}\end{array}$ & \multicolumn{2}{|c|}{$\begin{array}{l}78 / 10004 \\
8 \cdot 0\end{array}$} & \multicolumn{2}{|c|}{$\begin{array}{l}109 / 10108 \\
10 \cdot 8\end{array}$} & \multicolumn{2}{|c|}{$\begin{array}{c}106 / 10236 \\
10 \cdot 4\end{array}$} & \multicolumn{2}{|c|}{$\begin{array}{l}88 / 10507 \\
8 \cdot 4\end{array}$} & \multicolumn{2}{|c|}{$\begin{array}{c}112 / 11042 \\
10 \cdot 1\end{array}$} & \\
\hline $\begin{array}{l}\text { Model } 1 \\
\text { Q2-Q5 v. Q1 }\end{array}$ & $\begin{array}{l}1.00 \\
1.00\end{array}$ & $\begin{array}{l}\text { Ref. } \\
\text { Ref. }\end{array}$ & $\begin{array}{l}1 \cdot 38 \\
1 \cdot 30\end{array}$ & $\begin{array}{l}1 \cdot 03,1 \cdot 85 \\
1.02,1.66\end{array}$ & $1 \cdot 33$ & $0.99,1.79$ & $1 \cdot 10$ & $0.81,1.49$ & $1 \cdot 40$ & $1 \cdot 05,1 \cdot 87$ & $0 \cdot 17$ \\
\hline $\begin{array}{l}\text { Model } 2 \\
\text { Q2-Q5 v. Q1 }\end{array}$ & $\begin{array}{l}1.00 \\
1.00\end{array}$ & $\begin{array}{l}\text { Ref. } \\
\text { Ref. }\end{array}$ & $\begin{array}{l}1 \cdot 44 \\
1 \cdot 38\end{array}$ & $\begin{array}{l}1.06,1.95 \\
1.06,1.80\end{array}$ & $1 \cdot 40$ & $1 \cdot 01,1 \cdot 94$ & $1 \cdot 15$ & $0 \cdot 82,1 \cdot 61$ & $1 \cdot 43$ & $1 \cdot 06,1 \cdot 93$ & $0 \cdot 18$ \\
\hline $\begin{array}{l}\text { Model } 3 \\
\text { Q2-Q5 v. Q1 }\end{array}$ & $\begin{array}{l}1.00 \\
1.00\end{array}$ & $\begin{array}{l}\text { Ref. } \\
\text { Ref. }\end{array}$ & $\begin{array}{l}1.41 \\
1.35\end{array}$ & $\begin{array}{l}1.04,1.93 \\
1.03,1.76\end{array}$ & $1 \cdot 37$ & $0.99,1.90$ & $1 \cdot 12$ & $0.79,1.57$ & $1 \cdot 38$ & $1 \cdot 02,1 \cdot 87$ & 0.27 \\
\hline $\begin{array}{l}\text { Model } 4 \\
\text { Q2-Q5 v. Q1 }\end{array}$ & $\begin{array}{l}1.00 \\
1.00\end{array}$ & $\begin{array}{l}\text { Ref. } \\
\text { Ref. }\end{array}$ & $\begin{array}{l}1.42 \\
1.34\end{array}$ & $\begin{array}{l}1.05,1.93 \\
1.03,1.75\end{array}$ & $1 \cdot 36$ & $0.98,1 \cdot 89$ & $1 \cdot 13$ & $0 \cdot 80,1 \cdot 58$ & $1 \cdot 37$ & $1 \cdot 01,1 \cdot 85$ & $0 \cdot 32$ \\
\hline
\end{tabular}

Q1-Q5, quintiles of consumption; HR, hazard ratio; Ref., reference category.

Model 1: adjusted for sex and stratified for age.

Model 2: additionally adjusted for smoking (no response, non-smoker, former smoker and current smoker), leisure-time physical activity (metabolic equivalent score), total energy intake ( $\mathrm{J} / \mathrm{d}$ ) and BMI (kg/ $\mathrm{m}^{2}$ ). Model 3: As model 2 additionally adjusted for fast-food consumption.

"HR estimated with Cox regression and $95 \% \mathrm{Cl}$. If the $95 \% \mathrm{Cl}$ interval does not include 1.00 , the results are statistically significant (two-tailed $P<0.05$ ). 
incident depression for each of these categories were $1 \cdot 00$ (reference), $1 \cdot 02(0 \cdot 78,1 \cdot 33)$ and $1.49(1 \cdot 08,2 \cdot 06), P$ for trend $=0.02$ (data not shown in the tables).

Additional adjustment for the consumption of healthy food items did not change the reported associations (model 4, Tables 2 and 3). Neither did the results change when some correlates of health consciousness or proxies of an overall healthier lifestyle were considered as possible confounders (data not shown).

To avoid a possible reverse causation bias (i.e. participants who were subclinically depressed at baseline could change their diet or the reporting of their diet as a consequence of a pre-existing undiagnosed depression), the analyses were repeated after excluding those cases of depression reported in the first $6,12,18$ or 24 months of follow-up. In these analyses, only a little attenuation of the associations was observed. The percentage of change in the magnitude of the associations ranged from $0.6 \%$ (after excluding those participants diagnosed in the first 6 months of follow-up) to $7 \cdot 9 \%$ (after excluding those diagnosed in the first 12 months of follow-up) for the comparison between the highest (Q5) and the lowest (Q1) fast-food consumption quintile. In the case of commercial baked goods and for the comparison between Q2-Q5 and Q1 of consumption, the percentage of change ranged from $1 \cdot 2 \%$ (when those participants diagnosed in the first 6 months of follow-up were excluded) to $13.6 \%$ (after excluding participants diagnosed in the first 2 years of follow-up).

\section{Discussion}

The present study showed a positive dose-response relationship between the consumption of fast food and the risk of depression. Moreover, consumption of commercial baked goods was also positively associated to depressive disorders but not linearly.

To our knowledge, only one prospective study has analysed the effect of fast-food or commercial baked goods consumption on depression risk, obtaining similar results to those reported by our group. Akbaraly et al. found a direct and significant association between the adherence to a 'processed food pattern' and depressive symptoms using the CES-D scale after 5 years of follow-up ${ }^{(16)}$.

The Western dietary pattern, a food pattern described in several large American cohort studies ${ }^{(22)}$, is very close to the processed food pattern used by Akbaraly et al. ${ }^{(16)}$ and to the Western diet described by Jacka et al. ${ }^{(13)}$. This pattern has been associated with higher CVD risk and worse levels of biomarkers of endothelial dysfunction and inflammation ${ }^{(22-25)}$. Moreover, physiological and biological links between CVD, inflammation and depressive disorders have been repeatedly suggested ${ }^{(26,27)}$. Therefore, it is plausible that some mechanisms implicated in the genesis of CVD could be also shared by depression.
The high content of trans unsaturated fatty acids (TFA) in bakery and processed foods is probably an important contributor to the adverse effects of these dietary patterns ${ }^{(28,29)}$. The adverse effects of TFA on CVD are thought to be mediated by increases in plasma concentrations of LDL-cholesterol, reductions in HDL-cholesterol, pro-inflammatory changes, endothelial dysfunction and, possibly, also by insulin resistance and displacement of essential fatty acids from membranes ${ }^{(30-32)}$. Since depression is associated with a low-grade inflammatory status, endothelial dysfunction, worse lipid profiles and impaired insulin and glucose homeostasis ${ }^{(33-36)}$, the detrimental biological modifications caused by TFA with respect to CVD risk could also be responsible for a harmful effect of consumption of fast food and commercial baked goods on depression risk.

Commercial baked goods are also rich in carbohydrates. Abundant evidence exists regarding the role of carbohydrate and protein intakes on plasma concentrations of tryptophan and of large neutral amino acids (LNAA). Brain concentrations of tryptophan (serotonin's essential amino acid precursor) depend both on plasma tryptophan and on plasma concentration of LNAA which compete with tryptophan for blood-brain barrier transport. Several studies have found a higher decrease in plasma tryptophan than in plasma LNAA after the ingestion of a meal rich in proteins or in proteins plus fats ${ }^{(37)}$. Contrarily, carbohydrate meals, specially those containing carbohydrates with a high glycaemic index (GI), have been associated, though insulin secretion, with increases in the plasma tryptophan:LNAA ratio $^{(37)}$. Several experimental studies have suggested that a variation of $50 \%$ in the plasma tryptophan:LNAA ratio is sufficient to change significantly the release of serotonin ${ }^{(38)}$.

In an apparent contradiction with our previous explanation, some authors have defended that carbohydrate intake could improve mood or even relieve depression ${ }^{(39)}$. However, such effects seem to be mediated through psychological mechanisms and not through the nutritional properties of carbohydrates. The intake of a highcarbohydrate diet or a diet with a high GI or glycaemic load (GL) has been associated in the short term with rapid and immediate changes in serotonin levels and consequently with a relief of some psychological symptoms (e.g. in premenstrual syndrome $)^{(40)}$. However, these results cannot be directly extrapolated to a disease with a longer course and a longer induction period such as the depressive disorder. Actually, low-GI and/or low-GL diets have been associated with a reduced risk of $\mathrm{CHD}^{(41)}$, conditions with a similar course and probably with similar induction period as depression. The most likely biological explanation for this similarity might be related to endothelial dysfunction or low-grade inflammation. In fact, low-GI diets have been also associated with a lower level of pro-inflammatory cytokines and a better lipid profile ${ }^{(42)}$.

In the present analysis, although both fast food and commercial bakery goods contributed to depression risk, 
the role of each group of foods seemed to be quite different. Whereas fast-food consumption apparently increased the risk of depression linearly, the trend for commercial bakery goods suggested a threshold effect. Differences in composition of each of these foods could explain the reported results. The main sources of TFA in our cohort, in addition to some natural sources, are commercial bakery goods, margarine, pizza, croquets and fast-food hamburgers. So, the detrimental effect of these products could be explained by the high content in TFA of fast food and commercial bakery goods. Nevertheless, diet-depression relationships could differ because of the differences in carbohydrate and SFA contents of fast food and commercial bakery goods. In fact, some studies have suggested that high-fat, low-carbohydrate ketogenic diets can disrupt cognition ${ }^{(43)}$. Diets rich in saturated or total fats can increase free radical production and promote pro-inflammatory states ${ }^{(44,45)}$. These diets induced oxidative damage and inflammation is associated with reduced expression of BDNF (brain-derived neurotrophic factor), lower neuronal plasticity and poorer cognitive ability in animal models ${ }^{(45)}$. BDNF is a neurotrophin related to several actions such as synaptic plasticity, neuronal survival and differentiation. Moreover, its levels have been reduced among depressed patients ${ }^{(46)}$.

Some potential limitations of the study need to be addressed. Self-reporting of a clinical diagnosis or the use of medication was used a criterion to establish depression. Our validation study found low sensitivity $(0 \cdot 37)$ but very high specificity $(0.96)$ for the self-reported diagnosis of depression ${ }^{(19)}$. Theoretically, with perfect specificity, non-differential sensitivity of disease misclassification will not bias the relative risk estimate ${ }^{(47)}$. Similarly, although the validity and reliability of the FFQ have been evaluated $^{(18)}$, some degree of misclassification may exist in the dietary assessment. However, the misclassification being more probably non-differential, the bias will be probably towards the null. Moreover, only some food items (i.e. hamburgers, sausages and pizza) were used to assess the consumption of total fast food and commercial baked goods in our cohort. Since the consumption of other food items of fast food and commercial bakery goods is very low in our population, we do not consider that the exclusion of other food items has led to a measurement error. Although the prevalence of reported stress (diagnosed stress disorder) in our sample was really low (eight cases at baseline), some minor degree of subclinical stress might be more prevalent and it could partially explain our reported results. However, we controlled for a wide variety of potential confounders that are likely to be related to subclinical levels of stress and the results were robust. In this line of thought, another potential concern might be that participants with subclinical depression at the beginning of the study may have changed their food habits because of their mood disorder. In fact, when we excluded those cases of depression diagnosed during the first 2 years of follow-up, the magnitude of the associations was attenuated. However, although non-significant, the point estimate for the increment of risk associated with high consumption of fast food and commercial baked goods remained around $30 \%$. We acknowledge that we did not account for any variation in dietary intake during the follow-up period; diet was only collected at baseline, and some of the cases of depression were reported after 8 years of follow-up. For that reason, the induction period for a diet effect might be shorter than the time of follow-up of these late cases. Further studies are needed to complete this assessment using repeated measurements of diet. Finally, the lack of control of several potential confounders related to psychological features cautions about the interpretation of the findings. Several strengths of our study also deserve to be mentioned. They include its large sample size, its prospective design and the long-term follow-up, the multiple adjustments of our estimates for a variety of major potential confounders, the existence of published validation studies of our assessments, and the restriction to highly educated participants who are able to provide more reliable information.

In conclusion, our results show a potentially detrimental association between the consumption of fast food or commercial baked goods and the risk of depression. Thus, public health nutrition policies should take into account the detrimental effects of these kinds of products not only on CVD and its related risk factors but also on mental health. The legally permitted content of TFA in fast food and/or commercial bakery goods should be reviewed.

Nevertheless, replication of these findings in other study populations is required in order to confirm the reported associations and to be able to make public health recommendations.

\section{Acknowledgements}

This work was supported by the Spanish Government Instituto de Salud Carlos III, Fondo de Investigaciones Sanitarias (projects PI010619, PI030578, PI042241, PI040233, PI050976, PI070240, PI070312, PI0801943, PI090918, RD 06/0045 and G03/140) and the Navarra Regional Government (projects 36/2001, 43/2002, 41/2005 and 36/2008). The authors declare no conflicts of interest. A.S.-V. and M.A.M.-G. were responsible for the study concept and design, acquisition of data, obtaining funding and study supervision. A.S.-V. and E.T. performed the statistical analysis; A.S.-V. drafted the manuscript. All the authors were involved in a critical revision of the manuscript. The authors are indebted to the participants of the SUN Project for their continued cooperation and participants. They thank to other members of the SUN group: Carmen de la Fuente, Alfredo Martínez, María SeguíGómez, Maira Bes-Rastrollo, Juan Jose Beunza, Manuel 
Serrano-Martínez, Francisco Guillén-Grima, Zenaida Vázquez, Silvia Benito, Felipe Ortuño, Francisca Lahortiga, Javier Schlatter, Jorge Doreste and Lluis Serra-Majem.

\section{References}

1. World Health Organization (2009) Mental Health. Depression. Geneva: WHO.

2. World Health Organization (2008) The Global Burden of Disease 2004 Update. Geneva: WHO.

3. Colangelo LA, He K, Whooley MA et al. (2009) Higher dietary intake of long-chain omega-3 polyunsaturated fatty acids is inversely associated with depressive symptoms in women. Nutrition 25, 1011-1019.

4. Sánchez-Villegas A, Henríquez P, Figueiras A et al. (2007) Long chain omega-3 fatty acids intake, fish consumption and mental disorders in the SUN cohort study. Eur J Nutr 46, 337-346.

5. Sánchez-Villegas A, Doreste J, Schlatter J et al. (2009) Association between folate, vitamin $\mathrm{B}(6)$ and vitamin $\mathrm{B}(12)$ intake and depression in the SUN cohort study. J Hum Nutr Diet 22, 122-133.

6. Ford AH, Flicker L, Thomas J et al. (2008) Vitamins $\mathrm{B}_{12}, \mathrm{~B}_{6}$, and folic acid for onset of depressive symptoms in older men: results from a 2 -year placebo-controlled randomized trial. J Clin Psychiatry 69, 1203-1209.

7. Kyrozis A, Psaltopoulou T, Stathopoulos P et al. (2009) Dietary lipids and geriatric depression scale score among elders: The EPIC-Greece cohort. I Psychiatr Res $\mathbf{4 3}$, 763-769.

8. Wolfe AR, Ogbonna EM, Lim S et al. (2009) Dietary linoleic and oleic fatty acids in relation to severe depressed mood: 10 years follow-up of a national cohort. Prog Neuropsychopharmacol Biol Psychiatry 33, 972-977.

9. Sánchez-Villegas A, Delgado-Rodríguez M, Alonso A et al. (2009) Association of the Mediterranean dietary pattern with the incidence of depression: the Seguimiento Universidad de Navarra/University of Navarra follow-up (SUN) cohort. Arch Gen Psychiatry 66, 1090-1098.

10. Liu C, Xie B, Chou CP et al. (2007) Perceived stress, depression and food consumption frequency in the college students of China Seven Cities. Physiol Behav 92, 748-754.

11. Jeffery RW, Linde JA, Simon GE et al. (2009) Reported food choices in older women in relation to body mass index and depressive symptoms. Appetite 52, 238-240.

12. Mikolajczyk RT, El Ansari W \& Maxwell AE (2009) Food consumption frequency and perceived stress and depressive symptoms among students in three European countries. Nutr J 8, 31.

13. Jacka FN, Pasco JA, Mykletun A et al. (2010) Association of Western and traditional diets with depression and anxiety in women. Am J Psychiatry 167, 305-311.

14. Bonnet F, Irving K, Terra JL et al. (2005) Depressive symptoms are associated with unhealthy lifestyles in hypertensive patients with the metabolic syndrome. J Hypertens 23, 611-617.

15. Oliver G \& Wardle J (1999) Perceived effects of stress on food choice. Physiol Behav 66, 511-515.

16. Akbaraly TN, Brunner EJ, Ferrie JE et al. (2009) Dietary pattern and depressive symptoms in middle age. $\mathrm{Br} J$ Psychiatry 195, 408-413.

17. Segui-Gomez M, de la Fuente C, Vazquez Z et al. (2006) Cohort profile: the 'Seguimiento Universidad de Navarra' (SUN) study. Int J Epidemiol 35, 1417-1422.

18. Fernández-Ballart JD, Piñol JL, Zazpe I et al. (2010) Relative validity of a semi-quantitative food-frequency questionnaire in an elderly Mediterranean population of Spain. $\mathrm{BrJ}$ Nutr 103, 1808-1816.
19. Sanchez-Villegas A, Schlatter J, Ortuno F et al. (2008) Validity of a self-reported diagnosis of depression among participants in a cohort study using the Structured Clinical Interview for DSM-IV (SCID-I). BMC Psychiatry 8, 43.

20. Martínez-González MA, López-Fontana C, Varo JJ et al. (2005) Validation of the Spanish version of the physical activity questionnaire used in the Nurses' Health Study and the Health Professionals' Follow-up Study. Public Health Nutr 8, 920-927.

21. Kom EL, Graubard BI \& Midthune D (1997) Time-to-event analysis of longitudinal follow-up of a survey: choice of the time-scale. Am J Epidemiol 145, 72-80.

22. Hu FB, Rimm E, Smith-Warner SA et al. (1999) Reproducibility and validity of dietary patterns assessed with a foodfrequency questionnaire. Am J Clin Nutr 69, 243-249.

23. Lopez-Garcia E, Schulze MB, Fung TT et al. (2004) Major dietary patterns are related to plasma concentrations of markers of inflammation and endothelial dysfunction. $A m J$ Clin Nutr 80, 1029-1035.

24. Fung TT, Willett WC, Stampfer MJ et al. (2001) Dietary patterns and the risk of coronary heart disease in women. Arch Intern Med 161, 1857-1862.

25. Fung TT, Rimm EB, Spiegelman D et al. (2001) Association between dietary patterns and plasma biomarkers of obesity and cardiovascular disease risk. Am J Clin Nutr 73, 61-67.

26. Hamer M \& Chida Y (2009) Associations of very high C-reactive protein concentration with psychosocial and cardiovascular risk factors in an ageing population. Atherosclerosis 206, 599-603.

27. Vaccarino V, Johnson BD, Sheps DS et al. (2007) Depression, inflammation, and incident cardiovascular disease in women with suspected coronary ischemia: the National Heart, Lung, and Blood Institute-sponsored WISE study. J Am Coll Cardiol 50, 2044-2050.

28. Fernández-San Juan PM (2009) Trans fatty acids (tFA): sources and intake levels, biological effects and content in commercial Spanish food. Nutr Hosp 24, 515-520.

29. Ascherio A, Katan MB, Zock PL et al. (1999) Trans fatty acids and coronary heart disease. $N$ Engl J Med 340, 1994-1998.

30. Brouwer IA, Wanders AJ \& Katan MB (2010) Effect of animal and industrial trans fatty acids on HDL and LDL cholesterol levels in humans - a quantitative review. PLOS One 5, e9434.

31. Wallace SK \& Mozaffarian D (2009) Trans-fatty acids and nonlipid risk factors. Curr Atheroscler Rep 11, 423-433.

32. Mozaffarian D, Aro A \& Willett WC (2009) Health effects of trans-fatty acids: experimental and observational evidence. Eur J Clin Nutr 63, Suppl. 2, S5-S21.

33. Su S, Miller AH, Snieder H et al. (2009) Common genetic contributions to depressive symptoms and inflammatory markers in middle-aged men: the Twins Heart Study. Psychosom Med 71, 152-158.

34. Lavoie KL, Pelletier R, Arsenault A et al. (2010) Association between clinical depression and endothelial function measured by forearm hyperemic reactivity. Psychosom Med 72, 20-26.

35. Dimopoulos N, Piperi C, Salonicioti A et al. (2007) Characterization of the lipid profile in dementia and depression in the elderly. J Geriatr Psychiatry Neurol 20, 138-144.

36. Zeman M, Jirak R, Jachymova M et al. (2009) Leptin, adiponectin, leptin to adiponectin ratio and insulin resistance in depressive women. Neuro Endocrinol Lett 30, 387-395.

37. Wurtman RJ, Wurtman JJ, Regan MM et al. (2003) Effects of normal meals rich in carbohydrates or proteins on plasma tryptophan and tyrosine ratios. Am J Clin Nutr 77, 128-132.

38. Fernstrom JD \& Wurtman RJ (1972) Brain serotonin content: physiological regulation by plasma neutral amino acids. Science 178, 414-416. 
39. Christensen L \& Pettijohn L (2001) Mood and carbohydrate cravings. Appetite 36, 137-145.

40. Murakami K, Sasaki S, Takahashi Y et al. (2008) Dietary glycemic index is associated with decreased premenstrual symptoms in young Japanese women. Nutrition $\mathbf{2 4}$, 554-561.

41. Barclay AW, Petocz P, McMillan-Price J et al. (2008) Glycemic index, glycemic load, and chronic disease risk a meta-analysis of observational studies. Am J Clin Nutr 87, 627-637.

42. Levitan EB, Cook NR, Stampfer MJ et al. (2008) Dietary glycemic index, dietary glycemic load, blood lipids, and C-reactive protein. Metabolism 57, 437-443.

43. Zhao Q, Stafstrom CE, Fu DD et al. (2004) Detrimental effects of the ketogenic diet on cognitive function in rats. Pediatr Res 55, 498-506.
44. Pistell PJ, Morrison CD, Gupta S et al. (2010) Cognitive impairment following high fat diet consumption is associated with brain inflammation. J Neuroimmunol 219, 25-32.

45. Wu A, Ying Z \& Gomez-Pinilla F (2004) The interplay between oxidative stress and brain-derived neurotrophic factor modulates the outcome of a saturated fat diet on synaptic plasticity and cognition. Eur J Neurosci 19, 1699-1707.

46. Bocchio-Chiavetto L, Bagnardi V, Zanardini R et al. (2010) Serum and plasma BDNF levels in major depression: a replication study and meta-analyses. World J Biol Psychiatry 11, 763-773.

47. Greenland S \& Lash TL (2008) Bias analysis. In Modern Epidemiology, 3rd ed., pp. 359-380 [KJ Rothman, S Greenland and TL Lash, editors]. Philadelphia, PA: Lippincott Williams and Wilkins. 